\title{
SLC gene-modified dendritic cells mediate $T$ cell-dependent anti-gastric cancer immune responses in vitro
}

\author{
GANG XUE $^{1}$, YING CHENG ${ }^{2}$, FENG RAN $^{1}$, XIANHUI LI $^{1}$, \\ TAO HUANG $^{1}$, YONG YANG ${ }^{1}$ and YANBIAO ZHANG ${ }^{1}$ \\ Departments of ${ }^{1}$ Breast and Thyroid Surgery, ${ }^{2}$ Endocrinology, Chengdu Army General Hospital, \\ Chengdu 610083, P.R. China
}

Received September 24, 2012; Accepted November 2, 2012

DOI: $10.3892 /$ or.2012.2154

\begin{abstract}
Dendritic cells (DCs) are potent professional antigen-presenting cells (APCs) with the ability to prime naïve $\mathrm{T}$ cells, and play an important role in the initiation and regulation of immune responses. In this study, we constructed a recombinant adenovirus carrying the SLC gene (Ad-SLC), and detected the biological effects of Ad-SLC-modified DCs as an adjuvant for the initiation of gastric cancer immune responses. Human DCs were transfected with Ad-SLC and the recombinant adenovirus carrying the $\beta$-galactosidase gene, Ad-LacZ, respectively. Modified DCs were pulsed with the cell lysate antigen of SGC-7901 cells (a type of gastric cancer cell line) and co-cultured with autologous T cells. The T cells were harvested and incubated with SGC-7901 cells and the cytotoxic function of the $\mathrm{T}$ cells was detected. Based on the data, the expression of mature DC phenotypes CD83 and CCR7 was upregulated after transfection with Ad-SLC and the chemotaxis function of DCs was augmented after transfection with Ad-SLC. Moreover, the expression of RANTES in DCs was upregulated by Ad-SLC transfection, while expression levels of IL-12p70 and IL-10 were not significantly altered. When co-cultured with autologous T cells, DCs modified with the SLC gene and pulsed with SGC-7901 cell lysates significantly promoted the proliferation of autologous $\mathrm{T}$ cells and induced Th1 differentiation, and displayed a strong cytotoxicity to
\end{abstract}

Correspondence to: Dr Ying Cheng, Department of Endocrinology, Chengdu Army General Hospital, 270 Rongdu Road, Chengdu 610083, P.R. China

E-mail: kpardan@126.com

Abbreviations: DCs, dendritic cells; Ad-SLC, recombinant adenovirus carrying the SLC gene; Ad-LacZ, recombinant adenovirus encoding $\beta$-galactosidase; TAA, tumor-associated antigen; Ad-SLC-DCs, DCs transfected with adenovirus vector encoding the SLC gene; NTDCs, non-transfected DCs; Ad-LacZ-DCs, DCs transfected with the adenovirus vector encoding $\beta$-galactosidase; ifu, infectious units; LDH, lactate dehydrogenase

Key words: dendritic cells, secondary lymphoid tissue chemokine, gastric cancer, tumor immunity, gene therapy
SGC-7901 cells. In conclusion, Ad-SLC promoted DC maturation, enhancing the ability of DCs for T-cell chemotaxis and T-cell stimulation, and induced specific anti-gastric cancer cellular immunity. Recombinant Ad-SLC-modified DCs may be used as an adjuvant to induce an effective anti-gastric cancer immune response.

\section{Introduction}

Many tumors express tumor-associated antigens (TAAs). Antigen-presenting cells (APCs), such as dendritic cells (DCs) process and present TAAs to T cells, thereby eliciting a tumor-specific immune response (1). However, since TAAs are considered autologous, many tumor cells often escape antitumor immunosurveillance. Various factors affecting this immune escape include the limited expression of the major histocompatibility complex (MHC) antigens and costimulatory molecules, the production of immune inhibitory cytokines (2) and tumorigenic viruses that inhibit the development of DCs (3). Therefore, recruitment of professional APCs to the tumor site, upregulating the expression of the MHC and associated costimulatory molecules, and enhancing the T cell-primed capability of APCs may be essential for generating specific antitumor immune responses. DCs are the most functional of the professional APCs, with a unique ability to capture and process antigens in peripheral blood and tissues. To achieve this, DCs migrate to draining lymphoid organs, where they select rare antigen-specific $\mathrm{T}$ cells in order to initiate immune responses. DCs also present antigens to $\mathrm{CD} 4^{+}$ T-helper cells, which in turn regulate antigen-specific $\mathrm{CD}^{+}$ cytotoxic T cells and B cells, as well as non-antigen-specific macrophages, eosinophils (4) and natural killer (NK) cells (5).

The ability of DCs to capture, process and present antigens to lymphocytes, and to induce and sustain primary immune responses makes them optimal candidates for vaccination protocols in cancer (6-8). Advancements in the isolation and propagation of DCs in vitro include the use of DCs as adjuvants to stimulate antigen-specific $\mathrm{T}$ cell activation and anticancer immunity (9-11). In immunotherapeutics, DCs are pulsed with i) defined peptides of known sequences, ii) undefined acideluted peptides from autologous tumors, iii) apoptotic tumor cells, iv) whole tumor lysates, v) retroviral and adenoviral vectors, vi) tumor cell-derived RNA, vii) fusion of DCs with 
tumor cells, and viii) exosomes derived from DCs pulsed with tumor peptides (12-18). Adenovirus infection can induce DC differentiation, which can cause prolonged survival and resistance to spontaneous and Fas-mediated cell death. Adenoviral-transfected DCs can also augment T-cell and NK cell activation relevant to DC secretion of IL-12, resulting in protective antitumor immunity (19-21). In addition, intratumoral administration of adenoviral vectors expressing cytokine gene-modified DCs can enhance local and systemic antitumor effects and achieve tumor eradication $(22,23)$.

Chemokines comprise a family of proteins that cause leukocyte chemotaxis and activation, and are associated with the regulation of angiogenesis (24). The secondary lymphoid tissue chemokine (SLC, also named 6Ckine, Exodus-2 and TCA4) is a CC chemokine expressed in high endothelial venules, and in the $\mathrm{T}$ cell zones of the spleen and lymph nodes. These molecules strongly attract T cells and mature DCs. SLC recruits both Th1 cells and antigen-stimulated DCs into the $\mathrm{T}$ cell zones of secondary lymphoid organs, resulting in $\mathrm{T}$ cell activation (25-30). Gunn et al (31) reported that the homing of T cells and DCs to secondary lymphoid organs was significantly decreased in $\mathrm{plt}^{-} / \mathrm{plt}^{-}$(paucity of lymphoid node $\mathrm{T}$ cell) mice, which lack the SLC gene. In addition to its immunotherapeutic ability, SLC reportedly has a potent anti-angiogenesis effect when bound to the CXCR3 receptor (32). This evidence adds additional support for the use of SLC in cancer therapeutics.

The anticancer abilities of SLC provide the rationale to evaluate this chemokine in cancer immunotherapy. Intratumoral injections of recombinant SLC in mouse lung cancer models have demonstrated potent antitumor responses, and have led to complete tumor eradication in $40 \%$ of treated mice (33). In the spontaneous murine bronchoalveolar cell carcinoma model, a recombinant SLC protein injected into the auxiliary lymph node region led to a marked reduction in tumor burden, extensively accompanied by lymphocyte and DC infiltration of the tumors and enhanced organism survival (34).

Based on these previous results, we constructed and utilized herein an adenoviral vector expressing the human SLC protein (Ad-SLC) for transfecting human monocyte-derived DCs (Ad-SLC-DCs). We show that the Ad-SLC-DCs produce a SLC protein with SLC-dependent biologic activity, as evidenced by the capacity of this protein to attract $\mathrm{T}$ cells, and to mediate an anti-gastric cancer immune response.

\section{Materials and methods}

Construction of an adenoviral vector expressing the human SLC protein. The adenoviral construct (Ad-SLC) is an E1, E3-deleted, replication-deficient adenoviral serotype 5 vector, carrying the SLC cDNA. The SLC gene was amplified by RT-PCR (Reverse Transcription System; Promega, USA) from human lymph nodes, using the following primer pairs: forward, 5'-TTTAGATCTATGGCTCAGTCACTGGCTCTGAG-3' and reverse, 5'-CCCGTCGACCTATGGCCCTTTAGGGGTCT GTG-3'. The SLC cDNA amplicon was digested with BglII (Promega) and SalI, and was cloned into the BglII-SalI sites of the pDC316 vector (Microbix Biosystems, Inc., Canada) to generate pDC316-SLC. This recombinant plasmid was verified by restriction enzyme analyses and sequencing (data not shown). The recombinant pDC316-SLC plasmid was co-trans- fected with pBHGlox $\Delta \mathrm{E} 1,3 \mathrm{Cre}$ (plasmid containing the $\mathrm{E} 1$, E3-deleted adenovirus genome; Microbix Biosystems, Inc.) into HEK293 cells [American Type Culture Collection (ATCC), Manassas, VA] using Lipofectamine ${ }^{\mathrm{TM}} 2000$ (Invitrogen, USA). This produced the recombinant E1, E3-deleted adenovirus, Ad-SLC, following intracellular homologous recombination. Recombinant adenoviruses encoding $\beta$-galactosidase (Ad-LacZ) (BD Biosciences Clontech, USA), without the SLC cDNA inserts, were used as negative controls. The Ad-SLC clone was obtained when a typical cytopathic effect (CPE) was induced in the HEK293 cells. This clone was confirmed by PCR, RT-PCR, immunofluorescence and western blot assays. We obtained the viral stock by amplifying in HEK293 cells, and purifying with $\mathrm{CsCl}$ gradient centrifugation and dialysis. The clone was stored as glycerol stocks $(10 \% \mathrm{v} / \mathrm{v})$ at $-80^{\circ} \mathrm{C}$. The titers (infectious units, ifu) of each viral stock (including Ad-LacZ) were quantitated following the Adeno- $\mathrm{X}^{\mathrm{TM}}$ Rapid Titer kit user manual guidelines (BD Biosciences Clontech). We assayed for wild-type adenovirus contamination in each viral stock by PCR amplification of a fragment on the E1 region of the adenovirus genome, and plaque assaying in hepatocellular carcinoma HepG2 cells.

Generation of DCs and T cells. All healthy donors signed informed consent, and this study was approved by the Institutional Review Board of Chengdu Army General Hospital. The peripheral blood mononuclear cell (PBMC) samples were acquired from donor leukocyte-enriched buffy coats using gradient centrifugation with Ficoll-Paque ${ }^{\mathrm{TM}}$ Plus (Amersham Biosciences, Uppsala, Sweden). From these, we recovered the light density fraction from $\sim 45 \%$ of the interface. The $\mathrm{CD} 14^{+} \mathrm{PBMCs}$ were purified by positive selection using CD14+-labelled microbeads and MACS columns (Miltenyi Biotec, Germany). The $\mathrm{CD} 14^{+}$cells were resuspended at $2 \times 10^{6}$ cells $/ \mathrm{ml}$, and cultured in 6 -well cell culture plates (BD Falcon, USA) in RPMI-1640 (Invitrogen) supplemented with $5 \%$ human $\mathrm{AB}$ serum, $100 \mathrm{U} / \mathrm{ml}$ penicillin, $100 \mu \mathrm{g} / \mathrm{ml}$ streptomycin, $2 \mathrm{mmol} / 1$ glutamine (Invitrogen), $30 \mathrm{ng} / \mathrm{ml}$ recombinant human interleukin-4 (IL-4, specific activity $>5 \times 10^{6} \mathrm{U} / \mathrm{mg}$; Peprotech, Inc., USA) and $100 \mathrm{ng} / \mathrm{ml}$ recombinant human granulocyte-macrophage colony stimulating factor (GM-CSF, specific activity $>1 \times 10^{7} \mathrm{U} / \mathrm{mg}$; Peprotech, Inc.). Three days following incubation, the cells were fed with cytokines and incubated for another 3 days. After 6 days of culture, the adherent and non-adherent cells were harvested and washed three times with phosphate-buffered saline (PBS) and were used in subsequent experiments.

The $\mathrm{T}$ cells were purified from the $\mathrm{CD} 14^{+}$monocytedepleted PBMCs using positive selection on a nylon-wool column, and were cultured in RPMI-1640 complete medium, supplemented with $20 \mathrm{U} / \mathrm{ml}$ IL-2. The purity of the resulting $\mathrm{T}$ cells was roughly $92-97 \%$, as assessed by fluorescenceactivated cell sorter (FACS) analysis.

Adenoviral transfection and tumor antigen pulse of human DCs. Based on our recent study to determine the multiplicity of infection (MOI) and the transfection method, the optimal transfection efficiencies and cell viabilities were ensured using a centrifugation method at an MOI of 50 (data not shown). These optimal conditions were utilized throughout, for 
transfections with all of the recombinant adenoviruses $(35,36)$. Briefly, on Day 6 of the culture period, DCs were resuspended at $2 \times 10^{6}$ cells $/ \mathrm{ml}$ in serum-free RPMI-1640 medium and the recombinant adenoviruses were suspended in the same medium and adjusted to $1 \times 10^{8} \mathrm{ifu} / \mathrm{ml}$. DC samples $(500 \mu \mathrm{l})$ were mixed with $500 \mu \mathrm{l}$ of adenovirus (at an MOI of 50) in $1.5 \mathrm{ml}$ polypropylene tubes, and centrifuged (Eppendorf $5415 \mathrm{D}$ in a $37^{\circ} \mathrm{C}$ incubator, Germany) at $2000 \mathrm{x}$ g at $37^{\circ} \mathrm{C}$ for $2 \mathrm{~h}$. Meanwhile, $500 \mu 1$ of the DCs was mixed with $500 \mu 1$ of virus-free medium that served as the non-transfected control (NTDCs). After the transfections, the Ad-SLC-DCs, Ad-LacZ-DCs and NTDCs were washed three times with PBS, resuspended at $5 \times 10^{5}$ cells $/ \mathrm{ml}$ in complete medium, containing $30 \mathrm{ng} / \mathrm{ml} \mathrm{IL-4}$ and $100 \mathrm{ng} / \mathrm{ml} \mathrm{GM-CSF}$, and incubated in 12-well cell culture plates (BD Falcon). All cell cultures were performed at $37^{\circ} \mathrm{C}$ in a humidified incubator with $5 \% \mathrm{CO}_{2}$. After $24 \mathrm{~h}$, the DCs (except for those designated for the phagocytosis assay and phenotype analyses) were pulsed with $100 \mu \mathrm{g} / \mathrm{ml}$ of whole SGC7901 cell lysates (from a gastric cancer cell line), and incubated at $37^{\circ} \mathrm{C}$ for another $24 \mathrm{~h}$.

Flow cytometric analysis of the phenotype of DCs. Ad-SLC-DCs Ad-LacZ-DCs and NTDCs were harvested, and flow cytometry was performed using the following monoclonal antibodies: fluorescein isothiocyanate (FITC)-CD86, FITC-CD83, FITCHLA-DR, FITC-CD14, phycoerythrin (PE)-CD80, PE-CD1a, PE-CD11c and PE-CCR7 (BD Biosciences Pharmingen, USA). The cells were analyzed with a FACS, using an EPICS ${ }^{\circledR}$ Elite flow cytometer (Beckman Coulter, USA). These data were analyzed with WinMDI2.8 software.

SLC, RANTES, IL-12p70 and IL-10 assays. Two days after the transfections, the levels of SLC and RANTES in the cell supernatants were assayed, using the Quantikines ${ }^{\circledR}$ Human SLC/CCL21 immunoassay kit (R\&D Systems, USA) and the Human RANTES ELISA kit (Pierce Biotechnology, Inc., USA), respectively, according to the kit instructions. The sensitivities of these assays were 9.9 and $2 \mathrm{pg} / \mathrm{ml}$, respectively. Meanwhile, the cytokines IL-12p70 and IL-10 in the supernatants were detected with LiquidChip assay, using the Human Hcyto-60k-03 LINCOplex Multiplex kit (Linco Research, Inc., USA), according to the manufacturer's protocol. The data were analyzed using integrated system (IS) software (Qiagen, Germany). The LiquidChip kit detected the IL-12p70 and IL-10 at 2-10 pg/ml.

Phagocytosis assay. After $24 \mathrm{~h}$ of transfection (without being antigen pulsed), the DCs were harvested and placed in 24-well cell culture plates at a density of $5 \times 10^{5}$ cells/well, in triplicate. To each well 40,000 MW FITC-dextran (Sigma Chemical Co., USA) was added to a final concentration of $1 \mathrm{mg} / \mathrm{ml}$. The plates were incubated at $37^{\circ} \mathrm{C}$ for $2 \mathrm{~h}$, then the cells were washed three times with PBS, fixed with $2 \%$ paraformaldehyde and assayed for the fluorescence intensity and the percentage of FITC-dextran uptake using FACS analysis.

Chemotaxis and chemotaxis blocking assay. The chemotaxis function of the supernatant derived from the Ad-SLC-DCs, Ad-LacZ-DCs and NTDCs was assessed using Transwells ${ }^{\circledR}$ filter apparatus (Corning Costar Corp., USA). Briefly, we loaded
$600 \mu \mathrm{l}$ of culture supernatants from Day 8 DCs in 24-well plates (lower chamber) in duplicate, then placed 6.5-mm Transwells ${ }^{\circledR}$ filter inserts with $3.0-\mu \mathrm{m}$ pore size polycarbonate membranes in each well, and added $100 \mu \mathrm{l}$ of T cells $\left(2 \times 10^{6}\right.$ cells $\left./ \mathrm{ml}\right)$ to the filter inserts (upper chamber). RPMI-1640 containing 5\% human $\mathrm{AB}$ serum and $600 \mu \mathrm{l}$ of the recombinant human SLC protein $(0.1 \mathrm{ng} / \mu \mathrm{l}$; R\&D Systems) were used as negative and positive controls, respectively. For the chemotaxis blocking assay, we pre-incubated the Ad-SLC-DC-derived supernatants with neutralizing concentrations of recombinant human antiSLC monoclonal antibody (1:10 final concentration; R\&D Systems) for $1 \mathrm{~h}$ at room temperature. These pre-incubated samples were added to the lower chamber of the apparatus, replacing the supernatant in the chemotaxis assay. The plates were incubated at $37^{\circ} \mathrm{C}$ in $5 \% \mathrm{CO}_{2}$ for $4 \mathrm{~h}$. The filter inserts were removed from the wells, and $1 \times 10^{4} / 50 \mu \mathrm{l}$ of $15-\mu \mathrm{m}$ polystyrene beads were added to each well. The contents of each well were thoroughly mixed, harvested, washed three times in PBS, fixed with 2\% paraformaldehyde and analyzed using FACS analysis. The total number of migrating cells per sample was determined using the following formula: (Number of counted cells/number of counted beads) x 10,000.

T-cell stimulation. For the mixed leukocyte reaction (MLR), the Day 8 Ad-SLC-DCs, Ad-LacZ-DCs and the NTDCs were incubated with $25 \mu \mathrm{g} / \mathrm{ml}$ mitomycin A at $37^{\circ} \mathrm{C}$. After $30 \mathrm{~min}$, the DCs were harvested and washed three times with PBS (containing $1 \%$ human $\mathrm{AB}$ serum), and then combined with autologous $\mathrm{T}$ cells, at a dendritic cell:T cell (DC:T) ratio of 1:20 in $200 \mu \mathrm{l}$ RPMI-1640 complete medium, in round-bottom 96-well cell culture plates (Nunc, Denmark) in triplicate. The plates were incubated at $37^{\circ} \mathrm{C}$ in $5 \% \mathrm{CO}_{2}$ for $96 \mathrm{~h}$, followed by pulsation with $1 \mu \mathrm{Ci} /$ well of $\left[{ }^{3} \mathrm{H}\right]$ thymidine $\left({ }^{3} \mathrm{H}-\mathrm{TdR}\right.$, from AERE, Shanghai, China). The labeled cells were harvested onto a glass fiber filter paper after $16 \mathrm{~h}$. The amount of incorporated ${ }^{3} \mathrm{H}-\mathrm{TdR}$ [described as counts/min (cpm)] was detected using a LS6500 liquid scintillation counter (Beckman Coulter), and the stimulating index (SI) was calculated using the following formula: Experimental cpm - blank cpm/control cpm - blank cpm.

IL-2 and T-bet assay. On Day 8 of culture, each DC group was co-cultured with autologous, nylon-wool-purified T cells at a DC:T ratio of $1: 20\left(1 \times 10^{4}\right.$ DCs plus $2 \times 10^{5} \mathrm{~T}$ cells $)$ in $200 \mu \mathrm{l}$ RPMI-1640 complete medium in round-bottom 96-well cell culture plates (Nunc) in triplicate. The plates were incubated in $5 \% \mathrm{CO}_{2}$ at $37^{\circ} \mathrm{C}$. After $24 \mathrm{~h}$, the supernatants were collected, and the IL-2 concentrations were measured by ELISA, according to the manufacturer's protocol (BioSource, USA). The sensitivity of the IL-2 assay was $15 \mathrm{pg} / \mathrm{ml}$.

Meanwhile, each DC group ( $1 \times 10^{5}$ cells) was incubated with mitomycin $\mathrm{A}$ at $37^{\circ} \mathrm{C}$ for $30 \mathrm{~min}$, and then co-cultured with autologous $\mathrm{T}$ cells $\left(2 \times 10^{6}\right.$ cells) at $37^{\circ} \mathrm{C}$ in $5 \% \mathrm{CO}_{2}$ for $96 \mathrm{~h}$. Following this, the $\mathrm{T}$ cells were harvested and the total RNA was extracted using TRIzol ${ }^{\circledR}$ reagent (Invitrogen), according to the manufacturer's protocol. The level of T-bet mRNA expression was assessed by semi-quantitative RT-PCR (Reverse Transcription System; Promega), using the following primer pairs: forward, 5'-CCCAGATGATTGTGCTCCAG-3' and reverse, 5'-TCATGCTGACTGCTCGAAAC-3', with an expected PCR product of $450 \mathrm{bp}$. The $\beta$-actin PCR product 
A
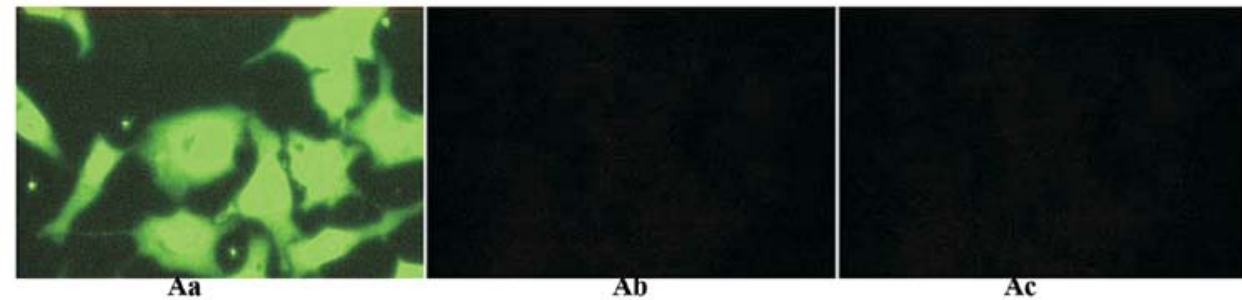

Ba

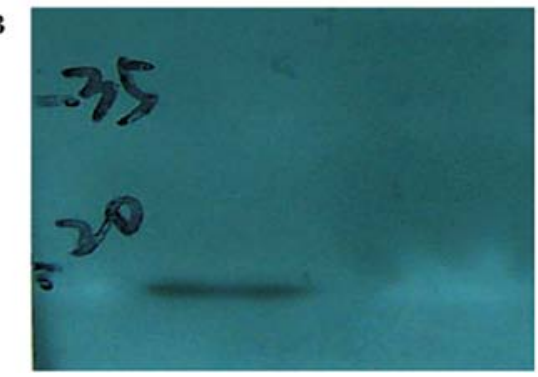

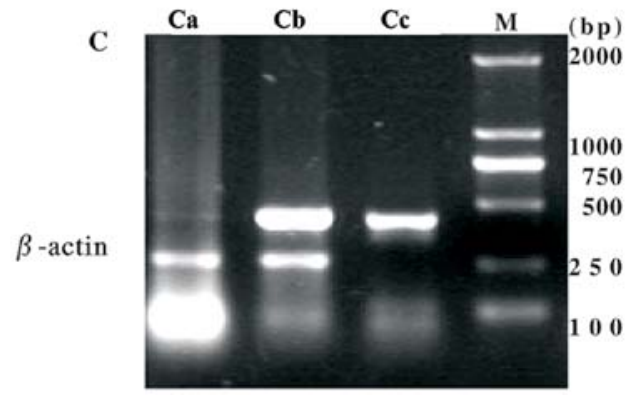

Figure 1. SLC mRNA and protein expression in HepG2 cells. (A) Immunofluorescence staining in HepG2 cells transfected with adenovirus vectors. Aa, Ad-SLC-transfected HepG2 cells (x200); Ab, Ad-LacZ-transfected HepG2 cells (x200); Ac, non-transfected HepG2 cells (x200). (B) Western blot analysis. Ba, Ad-SLC-transfected HepG2 cells, a 14-kDa band is observed; Bb, Ad-LacZ-transfected HepG2 cells. (C) SLC mRNA expression measured by RT-PCR. Lane Ca, Ad-LacZ-transfected HepG2 cells; lane, Cb, Ad-SLC-transfected HepG2 cells; lane Cc, SLC cDNA PCR amplicon as the positive control; lane M, DL2000 DNA marker.

(245 bp) was used as a baseline control. The T-bet and $\beta$-actin amplicons were visualized with electrophoresis on a $1 \%$ agarose gel containing $0.5 \mu \mathrm{g} / \mathrm{ml}$ ethidium bromide. The amplicon densities were analyzed with the Genetools Analysis Software, version 3.0 (SynGene Lab). The results were expressed as a ratio of the quantified T-bet product over the quantitated $\beta$-actin product.

Cytotoxicity assay. The SGC7901 cells were used as targets for detecting the cytotoxic function of the T cells which were stimulated separately with Ad-SLC-DCs, Ad-LacZ-DCs and NTDCs, using the CytoTox $96^{\circledR}$ Non-Radioactive Cytotoxicity Assay kit (Promega). The autologous nylon-wool-purified $\mathrm{T}$ cells were co-cultured with the DCs at a DC:T ratio of 1:20 on Day 8 of the DC culture period. After $96 \mathrm{~h}$, the T cells were harvested and incubated with tumor cells in round-bottom 96-well culture plates at an effector:target (E:T) ratio of 20:1 and 50:1, in triplicate. The controls including effector cell spontaneous lactate dehydrogenase (LDH) release, target cell spontaneous LDH release, target cell maximum LDH release, volume correction control and culture medium background were also set up in triplicate. The plate was centrifuged at $250 \mathrm{x} \mathrm{g}$ for $4 \mathrm{~min}$, and incubated in a humidified chamber at $37^{\circ} \mathrm{C}$ with $5 \% \mathrm{CO}_{2}$ for $4 \mathrm{~h}$. For the target cell maximum LDH release control, $20 \mu \mathrm{l}$ of lysis solution (10X) was added to the appropriate wells $45 \mathrm{~min}$ prior to harvesting the supernatants. After incubation, the plate was centrifuged at $250 \mathrm{x} g$ for an additional $4 \mathrm{~min}$. Supernatants $(50 \mu \mathrm{l})$ from all wells were transferred into the wells of a fresh flat-bottom 96-well assay plate. Reconstituted substrate mix $(50 \mu \mathrm{l})$ was added to this new assay plate. The plate was incubated in the dark at room temperature for $30 \mathrm{~min}$, and the absorbance (A) was measured at $490 \mathrm{~nm}$, following the addition of $50 \mu \mathrm{l}$ of stop solution.
The percent cytotoxicity was computed using the following formula: (Experimental A - culture medium background A) - (effector cell spontaneous A - culture medium background A) - (target cell spontaneous A - culture medium background A)/ (target cell maximum A - volume correction control A) - (target cell spontaneous A - culture medium background A) x 100.

The same cytotoxicity assay was performed using LoVo cell lysate (from a colon cancer cell line, as a different antigen control) pulsed DC-mediated T cells to kill SGC7901 cells.

Statistical analyses. One-way analysis of variance (ANOVA) test was used to compare differences among the Ad-SLC-DCs, Ad-LacZ-DCs and NTDC groups, using SPSS 17.0 statistical software. Statistical significance was determined at a P-value of $0.05(\mathrm{P}<0.05)$.

\section{Results}

Recombinant human Ad-SLC was successfully constructed and expressed SLC protein in eukaryocytes. The adenovirus vector containing the human SLC gene (Ad-SLC) was constructed successfully, as determined by PCR (data not shown). The titer of each viral stock (containing Ad-LacZ) was $1 \times 10^{10}-1.2 \times 10^{10}$ ifu $/ \mathrm{ml}$, as determined by detecting the signal of the anti-hexon antibody. Any wild-type adenoviral contamination was not detected by PCR and in the SGC7901 cells. SLC mRNAs were detected in the transfected HepG2 cells. SLC proteins (green fluorescence) were also found in the cytoplasm and membranes of the transfected cells. Western blot analysis with the anti-SLC antibody showed a immunoreactive band of the predicted size $(14 \mathrm{kDa})$ in the cells transfected with Ad-SLC. The cells transfected with the Ad-LacZ empty vector did not react in any of the parallel experiments (Fig. 1). 
CD83

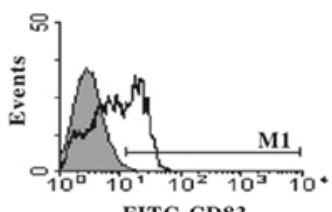

FITC-CD83

CD14
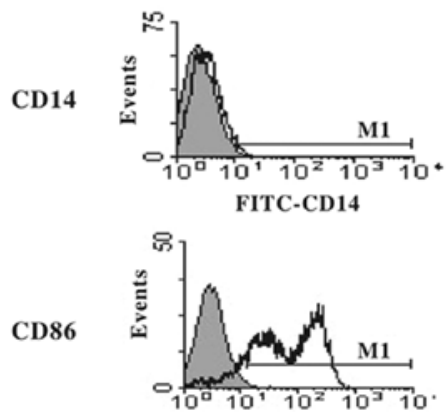

FITC-CD86

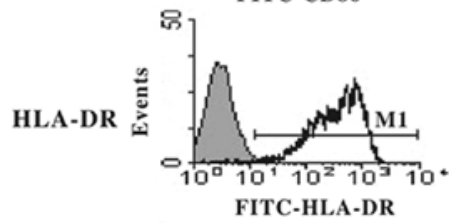

CD80

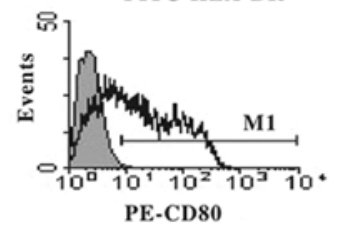

CCR7

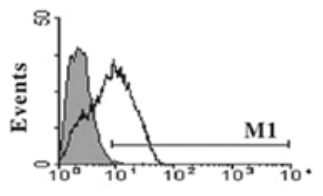

PE-CCR?

CD11c
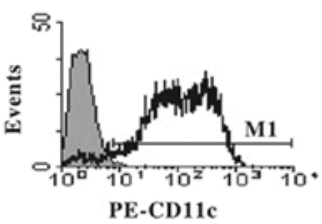

CD1a

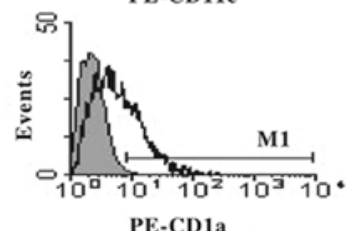

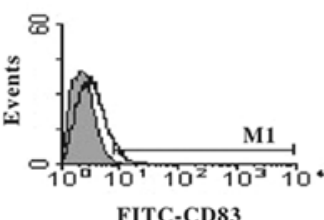

FITC-CD83
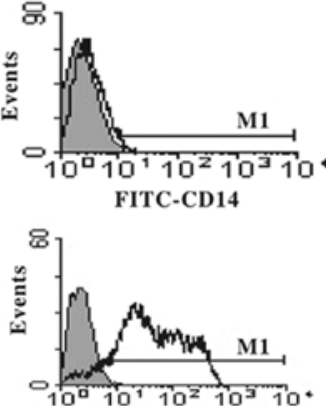

FITC-CD86
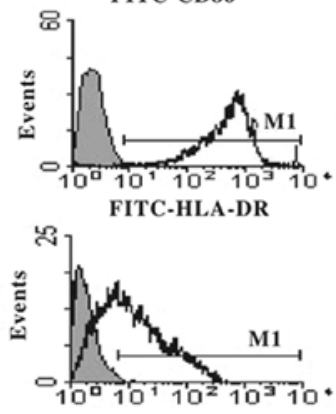

PE-CD80
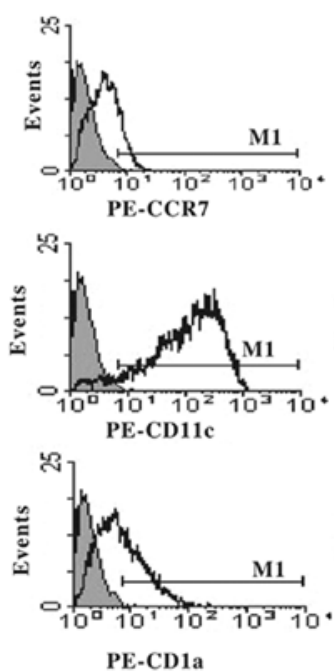

PE-CD1a
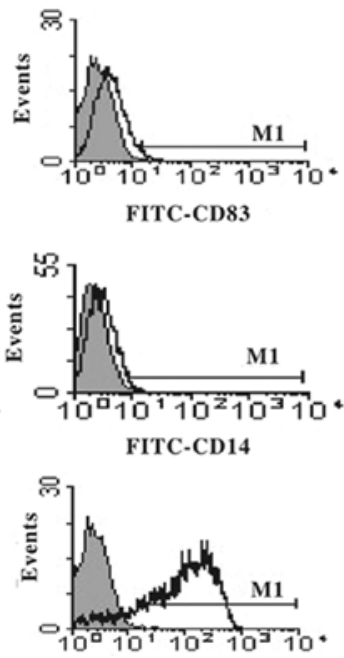

FITC-CD86
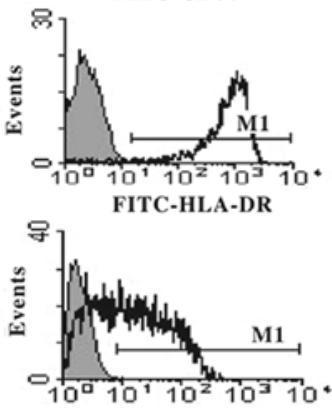

PE-CD80
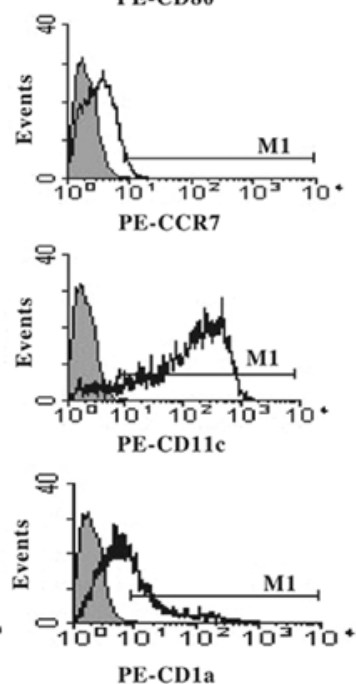

Figure 2. Phenotype of human DCs transfected with Ad-SLC. Figures show cell surface marker expression in each group of DCs at an MOI 50:1. Ad-SLC-DCs in the first column; Ad-LacZ-DCs in the second column; NTDCs in the third column; Solid filled lines represent isotype control, and bold lines represent the surface marker staining. Results represent five independent experiments.

The phenotype of mature DCs is upregulated after transfection with Ad-SLC. The phenotypes of the Ad-SLC-DCs, Ad-LacZ-DCs and NTDCs were characterized by flow cytometry $48 \mathrm{~h}$ after transfection. The expression of the DC surface markers was not significantly altered by transfection with recombinant adenovirus, with the exception of CD83, and CCR7. The immature DC phenotypes (CD83 ${ }^{\text {low }}, \mathrm{CCR} 7^{\text {low }}$ ) were preserved in Ad-LacZ-DCs and NTDCs, however, CD83 and CCR7 were significantly augmented in Ad-SLC-DCs when compared with the other groups. The costimulatory molecules CD80 and CD86, as well as the MHC HLA-DR molecules maintained high expression levels, not only in the adenovirus-transfected DCs, but also in the NTDCs (>90\%). This finding was identical as that for CD11c. The expression 

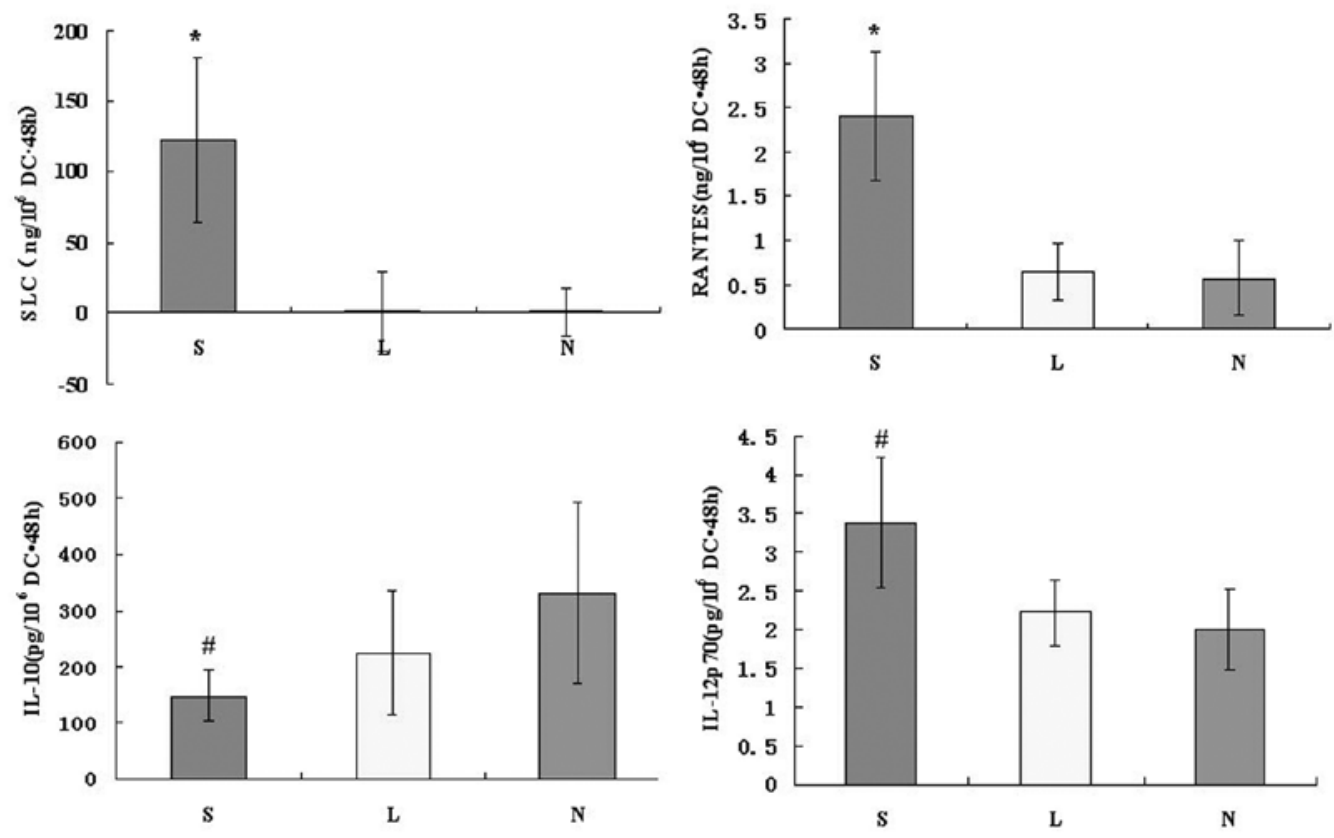

Figure 3. SLC, RANTES, IL-12p70 and IL-10 production by Ad-SLC-DCs. DCs $\left(1.0 x 10^{6}\right)$ were transfected with Ad-SLC and Ad-LacZ at an MOI of 50:1, by the centrifugal method. The chemokines SLC, RANTES and the cytokines IL-12p70, IL-10 in the supernatants of each DC group were measured by specific ELISA or by LiquidChip after $48 \mathrm{~h}$ of transfection. Values refer to chemokine/cytokine concentrations expressed in nanograms/picograms per million cells $48 \mathrm{~h}$ after transfection, and represent six separate experiments. S, Ad-SLC-DCs; L, Ad-LacZ-DCs; N, NTDCs. "P<0.05 when compared with other groups. ${ }^{\#} \mathrm{P}>0.05$ when compared with other groups.

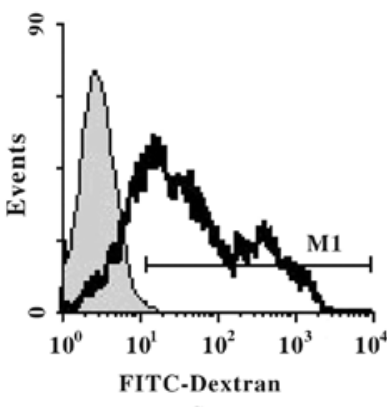

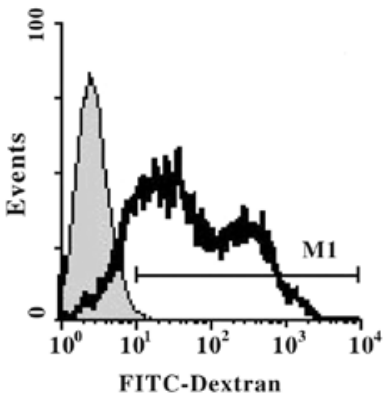

L

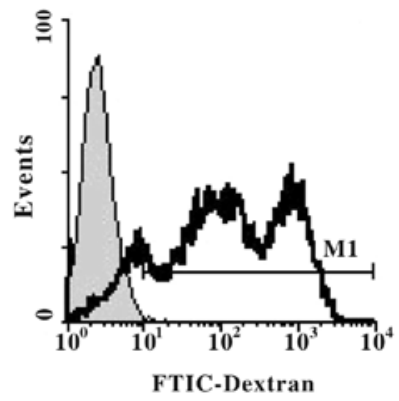

Figure 4. Phagocytosis of Ad-SLC-DCs. The percentage of FITC-dextran uptake by the DCs was assessed with FACS analysis after $24 \mathrm{~h}$ of tranduction. The data represent three separate experiments. S, Ad-SLC-DCs; L, Ad-LacZ-DCs; N, NTDCs. P>0.05 when compared among groups.

of CD1a and CD14 was maintained at a low level in all groups (Fig. 2; $\mathrm{P}<0.05)$.

SLC protein is produced by Ad-SLC-DCs. On culture Day 6, the immature human monocyte-derived DCs were transfected with Ad-SLC and Ad-LacZ. After 48 h, we assessed the SLC protein product using the anti-SLC antibody by ELISA. As a result, the amount of SLC protein from the Ad-SLC-DCs was $122.63 \pm 58.12 \mathrm{ng} / 10^{6}$ cells $\cdot 48 \mathrm{~h}$, while the Ad-LacZ-DCs and NTDCs produced $1.43 \pm 28.23$ and $1.00 \pm 17.09 \mathrm{ng} / 10^{6}$ cells $\cdot 48 \mathrm{~h}$ of SLC protein, respectively. Statistically, the amount of SLC proteins produced by Ad-SLC-DCs were significantly higher than those measured in any of the other two groups (Fig. 3; $\mathrm{P}<0.05$ ).
The chemokine RANTES is secreted by recombinant $A d-S L C-D C s$. After $48 \mathrm{~h}$ of exposure to the transfecting agents, the DCs were assayed for the presence of the chemokine RANTES and the cytokines IL-10 and IL-12p70 using specific ELISA and LiquidChip tests. The production of RANTES from the Ad-SLC-DCs was increased significantly above that of the Ad-LacZ-DCs and NTDCs (Fig. 3; F=25.56, $\mathrm{P}<0.05)$. However, the amounts of IL-12p70 and IL-10 proteins secreted from the Ad-SLC-DCs demonstrated no differences compared with the protein levels in the Ad-LacZ-DCs and NTDCs (Fig. 3; F=2.63, P>0.05).

The phagocytic capability of DCs is maintained throughout 24 h of transfection. To determine whether or not the phagocytic 


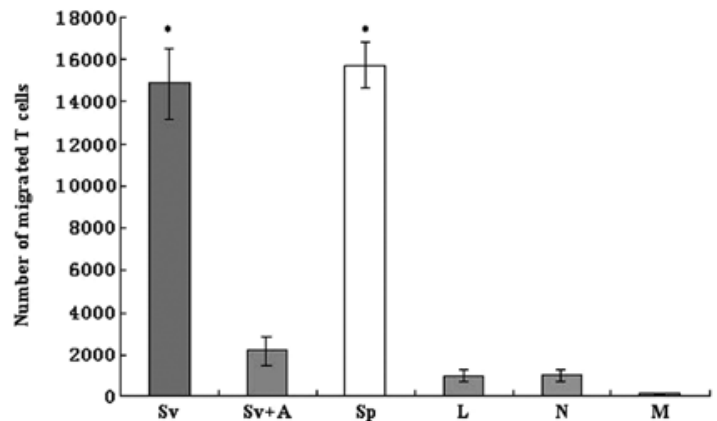

Figure 5. Ad-SLC-DCs augment naïve T cell chemotaxis, which was partially blocked by the anti-SLC monoclonal antibody. The results represent three independent experiments. Sv, Ad-SLC-DCs; Sv+A, Ad-SLC-DCs+antibody; Sp, SLC protein; L, Ad-LacZ-DCs; N, NTDCs; M, 5\% AB serum medium. ${ }^{*} \mathrm{P}<0.05$ when compared with the other groups.

function of the DCs was negatively impacted by adenoviral transfection, we measured FITC fluorescence in the infected DCs. We found that each DC group incorporated the FITCdextran particles, as evidenced by high fluorescence intensities; however, we observed no significant impact on the percentage of FITC-uptake in cells that had been transfected with the recombinant adenovirus. The phagocytic capability of the DCs remained intact within $24 \mathrm{~h}$ of adenoviral infection (Fig. 4; $\mathrm{F}=2.31, \mathrm{P}>0.05$ ).

Ad-SLC transfection augments the chemotaxis ability of $D C s$ and this capacity is partially blocked by the anti-SLC monoclonal antibody. The migration of naïve $\mathrm{T}$ cells to the
Ad-SLC-DCs was assessed using a Transwell chemotaxis assay apparatus. Our results showed that the Ad-SLC-DC supernatants, as well as the SLC protein, evoked enhanced $\mathrm{T}$ cell chemotaxis events, when compared to the Ad-LacZ-DC and NTDC supernatants alone or to the control medium (5\% $\mathrm{AB}$ serum) (Fig. 5; $\mathrm{F}=186.68, \mathrm{P}<0.05$ ). Yet, the enhanced attractive effects on T cells of the Ad-SLC-DC supernatants were inhibited significantly by the anti-SLC monoclonal antibody (Fig. 5; P<0.05). Notably, our data showed that only a partial chemoattractive activity of the Ad-SLC-DCs was reversed using the anti-SLC antibody. These results indicate that other proteins with attractant capabilities, such as RANTES, may exist in the DC supernatants, and that these auxiliary molecules likely account for the incomplete inhibition of $\mathrm{T}$ cell migration in the presence of the anti-SLC antibody.

Ad-SLC-DCs stimulate naïve T cell proliferation and induce Th1 differentiation. We investigated whether the Ad-SLC-DCs possess the ability to prime naïve $\mathrm{T}$ cells in vitro, using mitomycin A-treated DCs and ${ }^{3} \mathrm{H}-\mathrm{TdR}(\mathrm{cpm})$. Our results showed that the Ad-SLC-DCs were able to prime naïve T cells, as compared to the Ad-LacZ-DCs and the NTDCs (Fig. 6; $\mathrm{P}<0.05)$. We did not detect any significant differences in the T-cell priming capabilities of the Ad-LacZ-DCs and the NTDCs (Fig. 6; P>0.05).

To determine whether the Ad-SLC-DCs induce Th1 differentiation, IL-2 protein and T-bet mRNA expression in Ad-SLC-DC-transfected T cells was measured with ELISA or RT-PCR, respectively. The IL-2 protein secretion from the $\mathrm{T}$ cells co-cultured with the Ad-SLC-DCs was higher than those co-cultured with the Ad-LacZ-DCs and NTDCs
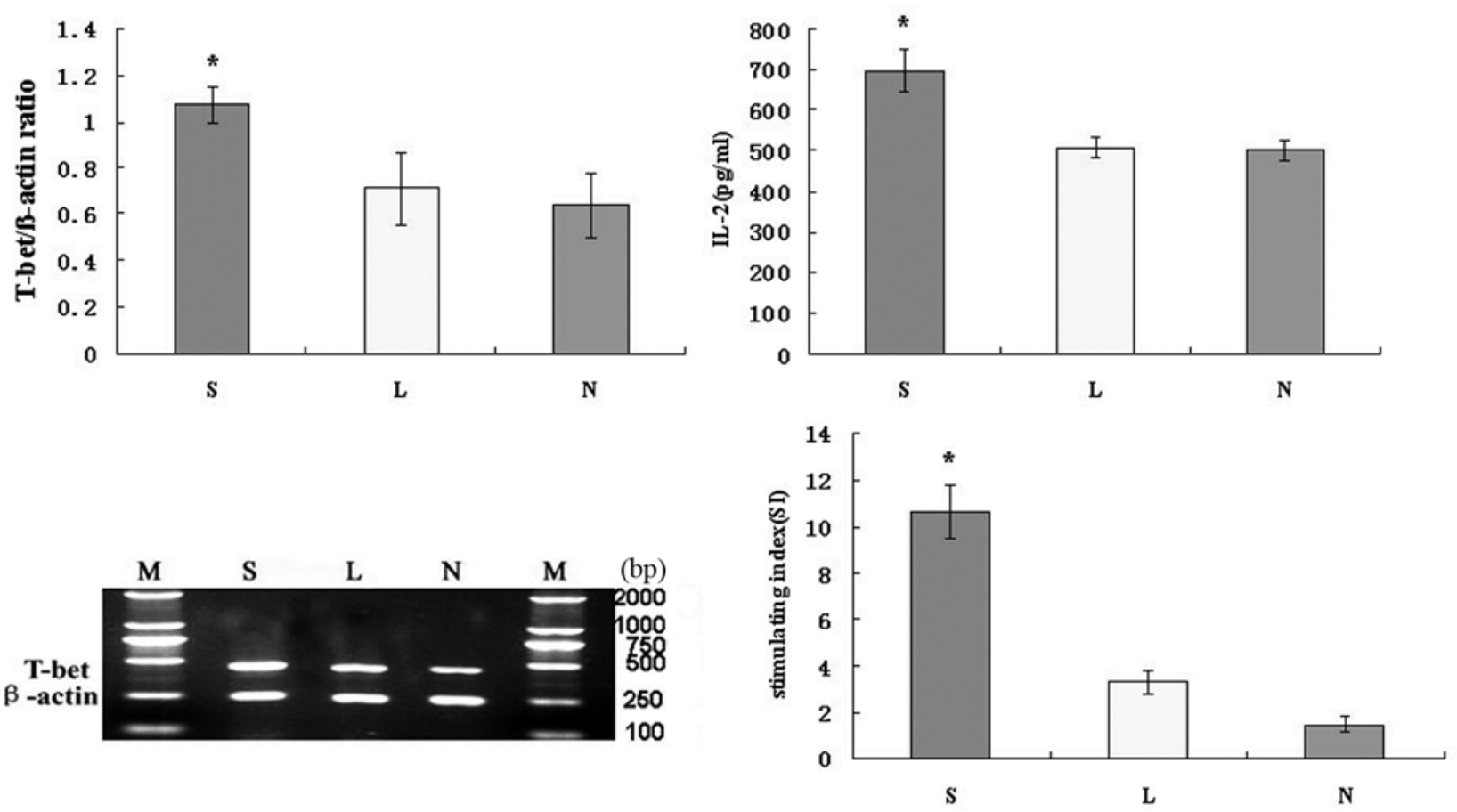

Figure 6. Ad-SLC-DCs promote T cell proliferation and Th1 polarization. Tumor antigen pulsed DCs were co-cultured with autologous T cells at a DC:T ratio of 1:20. The stimulating index (SI) was assayed using ${ }^{3} \mathrm{H}-\mathrm{TdR}$ incorporation method. The IL-2 and the T-bet expression by DC-stimulated T cells was measured with ELISA and semi-quantitative RT-PCR, respectively. The results are representative of five independent experiments. S, Ad-SLC-DCs; L, Ad-LacZ-DCs; N, NTDCs. "P<0.05 when compared with Ad-LacZ-DCs and NTDCs. 

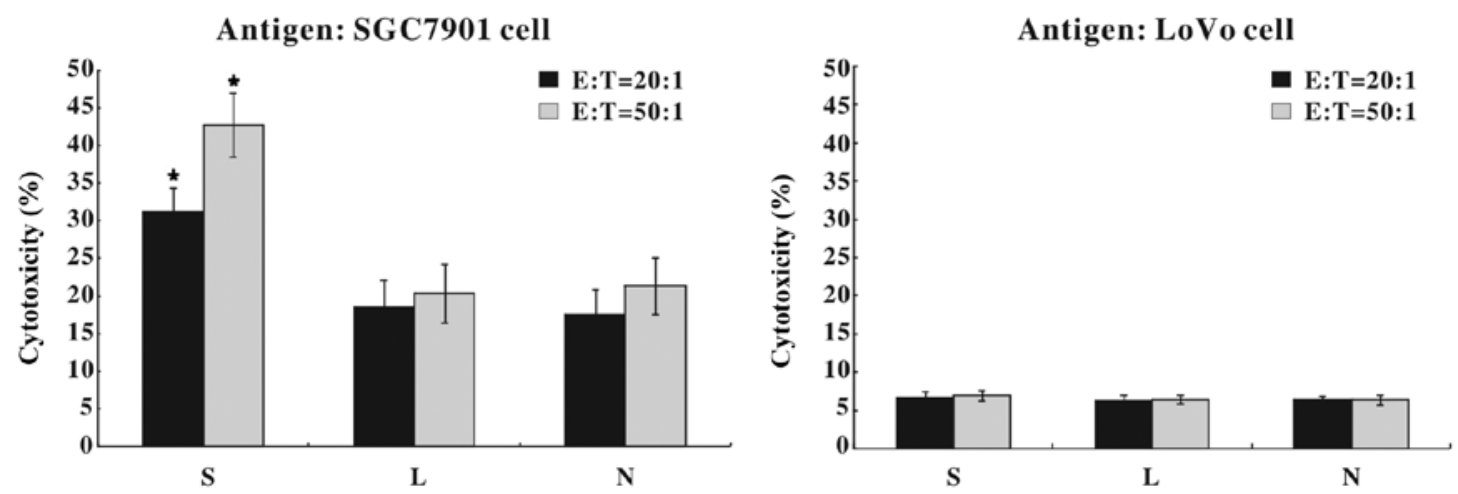

Figure 7. Cytotoxic function of T cells stimulated with Ad-SLC-DCs. Autologous T cells were co-cultured independently with each DC group, and then incubated with SGC7901 cells at different E:T ratios for $4 \mathrm{~h}$. The percent cytotoxicity (\%) was assessed using the LDH release method. The data represent five separate experiments. S, Ad-SLC-DCs; L, Ad-LacZ-DCs; N, NTDCs; E, effector cells; T, target cells. "P<0.05 when compared with the Ad-LacZ-DC and NTDC groups.

(Fig. 6; P<0.05). There was no significant difference in IL-2 secretion between the Ad-LacZ-DC and NTDC groups (Fig. 6; $\mathrm{P}>0.05)$. The level of T-bet mRNA expressed by the T cells co-cultured with the Ad-SLC-DCs was significantly higher than that by $\mathrm{T}$ cells exposed to the Ad-LacZ-DCs and NTDCs (Fig. 6; $\mathrm{P}<0.05$ ). There was no significant difference in T-bet expression levels between the Ad-LacZ-DC and NTDC groups (Fig. 6; P>0.05).

Ad-SLC-DCs induce specific anti-gastric cancer immunity. Following $24 \mathrm{~h}$ of recombinant adenoviral infection, the DCs were pulsed with whole SGC7901 or LoVo cell lysates as tumor antigens, co-cultured with autologous $\mathrm{T}$ cells and assayed for antitumor immunity. As shown in Fig. 7,31.25 $\pm 3.12 \%$ (E:T=20:1) or $42.78 \pm 4.25 \%$ (E:T=50:1) of the SGC7901 cells were killed by the cytotoxic T cells that had been primed with SGC7901 antigen-pulsed Ad-SLC-DCs, which was significantly higher than that in the other two DC groups $(\mathrm{P}<0.05)$. However, $\mathrm{T}$ cells primed with LoVo antigen-pulsed DCs showed little cytotoxicity against SGC7901 cells.

\section{Discussion}

Herein, we report the successful construction of an adenovirus vector expressing a chemokine protein (SLC), The protein is expressed in transfected eukaryocytes at the mRNA and protein level. It is a peptide with a molecular weight of about $14 \mathrm{kDa}$.

The ability of DCs to capture, process and present antigens to and subsequently prime $\mathrm{CD} 4^{+}$and $\mathrm{CD} 8^{+} \mathrm{T}$ cells makes them candidate adjuvants in anticancer immunotherapy. Previous studies using animal models have demonstrated that cytokine gene modification in DCs can enhance their antitumor capacity $(15,22,23)$. DCs are notoriously difficult to transfect using conventional methodologies and non-viral vectors, such as plasmid DNA/cationic liposome complexes, electroporation or $\mathrm{CaPO}_{4}$ coprecipitation (37). However, they are amenable to engineering with viral vectors such as the adenovirus, despite their lack of the cell surface Coxsackie B and adenovirus receptor (CAR). The suboptimal attachment of the adenovirus to DC surfaces leads to low gene transfer efficiency. This can be circumvented by increasing the contact between the adenovirus and the DC cell membrane by centrifugation or utilizing small volumes for transfection $(35,36,38)$ or by adding cationic liposomes to mediate the infection $(39,40)$. In this study, we used centrifugation to optimize the adenoviral transfection efficiency of the SLC gene into human monocyte-derived DCs.

Commonly, immature DCs are generated from monocytes that have been cultured for 5-7 days with GM-CSF and IL-4. Mature DCs are harvested after exposure to microbial, proinflammatory or T cell-derived stimuli such as TNF $\alpha$, IL-1 $\beta$, IFN $\alpha$, IFN $\gamma$ and PGE2 for 2-3 days. Our findings indicated that in addition to the high level expression of CD80, CD86, CD11c and HLA-DR, the transfected DCs required 2 additional days in culture to express sufficient levels of the mature markers CD83 and CCR7 on the surfaces of the Ad-SLC-DCs. This latter finding indicates that the secreted SLC protein in the tranduced DCs can partially auto-promote their phenotypic maturation. Moreover, it demonstrated enhanced DC antigenpresentation and subsequent $\mathrm{T}$ cell activation. Overall, our data suggest that DCs transfected with Ad-SLC can upregulate the expression of costimulatory molecules and the MHC complex, and promote DC maturation. This latter observation is profound, considering that the phagocytic capability, and thus the antigen-capture capacity of the DCs was maintained even after $24 \mathrm{~h}$ of transfection. Thus, we determined that we can pulse DCs with tumor antigens within $24 \mathrm{~h}$ of adenovirusmediated gene modification, and it will not decrease the ability of DCs to uptake these antigens.

In this study, we also found that the cultural supernatants of the Ad-SLC-DCs augmented the chemoattraction of DCs to nylon-wool-purified $\mathrm{T}$ cells. This function was partially blocked by the anti-SLC monoclonal antibody. We did not find this effect in the Ad-LacZ-DC or the NTDC supernatants. This result demonstrates that Ad-SLC imbued the transfected DCs with an attractant(s) to naïve T cells. Thus, intratumoral administration of Ad-SLC-modified DCs appears to be an effective strategy for cancer immunotherapy by attracting $\mathrm{T}$ cells to tumor sites, and then presenting the tumor antigens to the $\mathrm{T}$ cells.

SLC can recruit both T cells and matured DCs into the T cell zones of secondary lymphoid organs via CCR7, a chemo- 
kine receptor belonging to the subfamily of $\mathrm{G}$ protein-coupled seven-transmembrane receptors (41-43). This recruitment converges the immune response elements, including $\mathrm{T}$ cells and mature antigen-loaded DCs to the sites of SLC production, resulting in $\mathrm{T}$ cell activation and an antitumor response $(26,33)$. Our study showed that Ad-SLC augmented the CCR7 expression in the transfected DCs, and that the Ad-SLC-DCs produced the SLC protein to attract T cells. Thus, the Ad-SLCmodified DCs created a microenvironment, inhabited by co-localized T cells and mature DCs.

In contrast to immunization with purified peptide antigens such as $\alpha$ fetoprotein (AFP) or carcinoembryonic antigen (CEA), whole tumor cell lysate immunizations can provide DCs with the entire repertoire of available tumor antigens. This may increase the likelihood of antitumor immune responses and reduce the potential of a phenotypic-modulated tumor resistance. In the study presented herein, we transfected DCs with Ad-SLC, and then pulsed the transfectants with whole-cell SGC7901 lysates. Although the secretion of cytokines IL-12p70 and IL-10 from DCs transfected with Ad-SLC was not altered, we found that Ad-SLC significantly augmented the production of immunoenhancing chemokine, RANTES, in the transfected DCs, as compared to that in the Ad-LacZ-DCs and in the NTDCs. RANTES can stimulate $\mathrm{T}$ cell activation through the $\mathrm{T}$ cell receptor (TCR), characterized by increased secretion of IL-2 and IL-5, upregulation of IL-2 receptors and enhanced cellular proliferation. Moreover, RANTES activates antigen-specific cytotoxic $\mathrm{T}$ cells at high concentrations through self-aggregation on the cell surface (44-47). Therefore, our findings that the RANTES production was increased in the Ad-SLC-modified DCs predict that the Ad-SLC-modified DCs may polarize the immune response to the Th1 phenotype, and increase the cytolytic activity of $\mathrm{T}$ cells, subsequently inducing a potent antitumor immunity as an adjuvant.

Subsequent studies revealed that $\mathrm{T}$ cell proliferation was significantly stimulated by the Ad-SLC-DCs. This enhancement might have been produced by the SLC-induced DC maturation and by the DC secretion of RANTES and SLC. SLC can stimulate the proliferation of $\mathrm{CD}^{+}$and $\mathrm{CD}^{+} \mathrm{T}$ cells and induces Th1 polarization $(48,49)$. We also determined that the Ad-SLC-DCs induced Th1 polarization, which is evidenced by the enhanced expression of IL-2 and T-bet mRNA in the T cells. Interestingly, our findings demonstrated a hitherto unknown capability of the Ad-SLC-DCs to increase $\mathrm{T}$ cell abundance and hence proliferation and Th1 polarization evidenced by upregulation of IL-2 and T-bet expression in $\mathrm{T}$ cells.

Finally, our investigations revealed that the survival of the gastric cancer cells, SGC7901, was significantly reduced after they were mixed with T cells primed with the Ad-SLC-modified SGC7901 cell antigen-loaded DCs. The $\beta$-galactosidasemodified DCs and non-transfected DCs did not possess the anti-gastric cancer adjuvant function of the Ad-SLC-DCs. Presumably, this may be because the SLC chemokine is required for a full adjuvant effect.

In summary, the Ad-SLC-modified DCs maintained their capacity of phagocytosis within $24 \mathrm{~h}$ of transfection, indicating that they also uptake antigens. After an additional $24 \mathrm{~h}$, the Ad-SLC vector upregulated the expression of the MHC class II,
CCR7, CD83 and costimulators on the DC surfaces. These DCs attracted naïve $T$ cells and underwent intense maturation. After being pulsed by tumor antigens, the Ad-SLC-DCs secreted high levels of immunoenhancement chemokine SLC and RANTES, induced T cell proliferation and Th1 differentiation, leading to antitumor cytotoxic responses. In short, the Ad-SLC promotes DC maturation, enhances antigen presentation and $\mathrm{T}$ cell stimulation, and induces strong antitumor immunities. Our study indicates that intratumoral administration of Ad-SLC-modified DCs may promote colocalization of T cells and DCs in targeted tumor sites, and my eradicate tumors through a $\mathrm{T}$ cell-dependent mechanism.

\section{Acknowledgements}

This study was supported by the Elite Training Fund of Chengdu Army General Hospital.

\section{References}

1. Huang AY, Golumbek P, Ahmadzadeh M, Jaffee E, Pardoll D and Levitsky $\mathrm{H}$ : Role of bone marrow-derived cells in presenting MHC class I-restricted tumor antigens. Science 264: 961-965, 1994.

2. Restifo NP, Esquivel F, Kawakami Y, Yewdell JW, Mulé JJ, Rosenberg SA and Bennink JR: Identification of human cancers deficient in antigen processing. J Exp Med 177: 265-272, 1993.

3. Li L, Liu D, Hutt-Fletcher L, Morgan A, Masucci MG and Levitsky V: Epstein-Barr virus inhibits the development of dendritic cells by promoting apoptosis of their monocyte precursors in the presence of granulocyte macrophage-colonystimulating factor and interleukin-4. Blood 99: 3725-3734, 2000.

4. Lambrecht BN, Salomon B, Klatzmann D and Pauwels RA: Dendritic cells are required for the development of chronic eosinophilic airway inflammation in response to inhaled antigen in sensitized mice. J Immunol 160: 4090-4097, 1998.

5. Banchereau J and Steinman RM: Dendritic cells and the control of immunity. Nature 392: 245-252, 1998.

6. Steinman RM, Pack M and Inaba K: Dendritic cells in the T-cell areas of lymphoid organs. Immunol Rev 156: 25-37, 1997.

7. Tan MC, Mommaas AM, Drijfhout JW, Jordens R, Onderwater JJ, Verwoerd D, Mulder AA, van der Heiden AN, Scheidegger D, Oomen LC, Ottenhoff TH, Tulp A, Neefjes JJ and Koning F: Mannose receptor mediated uptake of antigens strongly enhances HLA class II-restricted antigen presentation by cultured dendritic cells. Eur J Immunol 27: 2426-2435, 1997.

8. Nair SK, Hull S, Coleman D, Gilboa E, Lyerly HK and Morse MA: Induction of carcinoembryonic antigen (CEA)-specific cytotoxic T-lymphocyte responses in vitro using autologous dendritic cells loaded with CEA peptide or CEA RNA in patients with metastatic malignancies expressing CEA. Int J Cancer 82: 121-124, 1999.

9. Timmerman JM and Levy R: Dendritic cell vaccines for cancer immunotherapy. Annu Rev Med 50: 507-529, 1999.

10. Lodge PA, Jones LA, Bader RA, Murphy GP and Salgaller ML: Dendritic cell-based immunotherapy of prostate cancer: immune monitoring of a phase II clinical trial. Cancer Res 60: 829-833, 2000.

11. Nestle FO, Alijagic S, Gilliet M, Sun Y, Grabbe S, Dummer R, Burg G and Schadendorf D: Vaccination of melanoma patients with peptide or tumor lysate-pulsed dendritic cells. Nat Med 4: 328-332, 1998.

12. Bell D, Young JW and Banchereau J: Dendritic cells. Adv Immunol 72: 255-324, 1999.

13. Henderson RA, Nimgaonkar MT, Watkins SC, Robbins PD, Ball ED and Finn OJ: Human dendritic cells genetically engineered to express high levels of the human epithelial tumor antigen mucin (MUC-1). Cancer Res 56: 3763-3770, 1996.

14. Ribas A, Bui LA, Butterfield LH, Vollmer CM, Jilani SM, Dissette VB, Glaspy JA, McBride WH and Economou JS: Antitumor protection using murine dendritic cells pulsed with acid-eluted peptides from in vivo grown tumors of different immunogenicities. Anticancer Res 19: 1165-1170, 1999. 
15. Miller PW, Sharma S, Stolina M, Butterfield LH, Luo J, Lin Y, Dohadwala M, Batra RK, Wu L, Economou JS and Dubinett SM: Intratumoral administration of adenoviral interleukin 7 genemodified dendritic cells augments specific antitumor immunity and achieves tumor eradication. Hum Gene Ther 11: 53-65, 2000.

16. Cao X, Zhang W, He L, Xie Z, Ma S, Tao Q, Yu Y, Hamada H and Wang J: Lymphotactin gene-modified bone marrow dendritic cells act as more potent adjuvants for peptide delivery to induce specific antitumor immunity. J Immunol 161: 6238-6244, 1998.

17. Celluzzi CM and Falo LD Jr: Physical interaction between dendritic cells and tumor cells results in an immunogen that induces protective and therapeutic tumor rejection. J Immuno 160: 3081-3085, 1998.

18. Ribas A, Butterfield LH, McBride WH, Jilani SM, Bui LA, Vollmer CM, Lau R, Dissette VB, Hu B, Chen AY, Glaspy JA and Economou JS: Genetic immunization for the melanoma antigen MART-1/Melan-A using recombinant adenovirus-transfected murine dendritic cells. Cancer Res 57: 2865-2869, 1997.

19. Lyakh LA, Koski GK, Young HA, Spence SE, Cohen PA and Rice NR: Adenovirus type 5 vector induces dendritic cell differentiation in human $\mathrm{CD} 14^{+}$monocytes cultured under serum-free conditions. Blood 99: 600-608, 2002.

20. Lundqvist A, Choudhury A, Nagata T, Andersson T, Quinn G, Fong T, Maitland N, Pettersson S, Paulie S and Pisa P: Recombinant adenovirus vector activates and protects human monocyte derived dendritic cells from apoptosis. Hum Gene Ther 13: 1541-1549, 2002

21. Miller G, Lahrs S, Pillarisetty VG, Shah AB and DeMatteo RP: Adenovirus infection enhances dendritic cell immunostimulatory properties and induces natural killer and T-cell-mediated tumor protection. Cancer Res 62: 5260-5266, 2002.

22. Kirk CJ, Hartigan-O'Connor D and Mulé JJ: The dynamics of the $\mathrm{T}$ cell antitumor response: chemokine-secreting dendritic cells can prime tumor-reactive T cells extranodally. Cancer Res 61: 8794-8802, 2001.

23. Kirk CJ, Hartigan-O'Connor D, Nickoloff BJ, Chamberlain JS, Giedlin M, Aukerman L and Mule JJ: T cell-dependent antitumor immunity mediated by secondary lymphoid tissue chemokine: augmentation of dendritic cell-based immunotherapy. Cancer Res 61: 2062-2070,2001

24. Baggiolini M, Dewald B and Moser B: Human chemokines: an update. Annu Rev Immunol 15: 675-705, 1997.

25. Gunn MD, Tangemann K, Tam C, Cyster JG, Rosen SD and Williams LT: A chemokine expressed in lymphoid high endothelial venules promotes the adhesion and chemotaxis of naïve T lymphocytes. Proc Natl Acad Sci USA 95: 258-263, 1998.

26. Cyster JG: Chemokines and the homing of dendritic cells to the T cell areas of lymphoid organs. J Exp Med 189: 447-450, 1999.

27. Chan VW, Kothakota S, Rohan MC, Panganiban-Lustan L, Gardner JP, Wachowicz MS, Winter JA and Williams LT: Secondary lymphoid-tissue chemokine (SLC) is chemotactic for mature dendritic cells. Blood 93: 3610-3616, 1999.

28. Hromas R, Kim CH, Klemsz M, Krathwohl M, Fife K, Cooper S, Schnizlein-Bick $\mathrm{C}$ and Broxmeyer HE: Isolation and characterization of Exodus-2, a novel CC chemokine with a unique 37 amino acid carboxyl-terminal extension. J Immunol 159: $2554-2558,1997$

29. Willimann K, Legler DF, Loetscher M, Roos RS, Delgado MB, Clark-Lewis I, Baggiolini M and Moser B: The chemokine SLC is expressed in T cell areas of lymph nodes and mucosal lymphoid tissues and attracts activated T cells via CCR7. Eur J Immunol 28: 2025-2034, 1998.

30. Nagira M, Imai T, Hieshima K, Kusuda J, Ridanpää M, Takagi S, Nishimura M, Kakizaki M, Nomiyama $\mathrm{H}$ and Yoshie $\mathrm{O}$ : Molecular cloning of a novel human CC chemokine secondary lymphoid-tissue chemokine that is a potent chemoattractant for lymphocytes and mapped to chromosome 9p13. J Biol Chem 272: 19518-19524, 1997.

31. Gunn MD, Kyuwa S, Tam C, Kakiuchi T, Matsuzawa A, Williams LT and Nakano H: Mice lacking expression of secondary lymphoid organ chemokine have defects in lymphocyte homing and dendritic cell localization. J Exp Med 189: 451-460, 1999.
32. Soto H, Wang W, Strieter RM, Copeland NG, Gilbert DJ, Jenkins NA, Hedrick J and Zlotnik A: The CC chemokine SLC binds the CXC chemokine receptor CXCR3. Proc Natl Acad Sci USA 95: 8205-8210, 1998.

33. Sharma S, Stolina M, Luo J, Strieter RM, Burdick M, Zhu LX, Batra RK and Dubinett SM: Secondary lymphoid tissue chemokine mediates $\mathrm{T}$ cell-dependent antitumor responses in vivo. J Immunol 164: 4558-4563, 2000.

34. Sharma S, Stolina M, Zhu L, Lin Y, Batra R, Huang M, Strieter R and Dubinett SM: Secondary lymphoid organ chemokine reduces pulmonary tumor burden in spontaneous murine bronchoalveolar cell carcinoma. Cancer Res 61: 6406-6412, 2001.

35. Nishimura N, Nishioka Y, Shinohara T, Ogawa H, Yamamoto S, Tani $\mathrm{K}$ and Sone S: Novel centrifugal method for simple and highly efficient adenovirus-mediated green fluorescence protein gene transfection into human monocyte-derived dendritic cells. J Immunol Methods 253: 113-124, 2001.

36. Nishimura N, Nishioka Y, Shinohara T and Sone S: Enhanced efficiency by centrifugal manipulation of adenovirus-mediated interleukin 12 gene transduction into human monocyte-derived dendritic cells. Hum Gene Ther 12: 333-346, 2001.

37. Arthur JF, Butterfield LH, Roth MD, Bui LA, Kiertscher SM, Lau R, Dubinett S, Glaspy J, McBride WH and Economou JS: A comparison of gene transfer methods in human dendritic cells. Cancer Gene Ther 4: 17-25, 1997.

38. Zhong L, Granelli-Piperno A, Choi Y and Steinman RM: Recombinant adenovirus is an efficient and non-perturbing genetic vector for human dendritic cells. Eur J Immunol 29: 964-972, 1999 .

39. Fasbender A, Zabner J, Chillón M, Moninger TO, Puga AP, Davidson BL and Welsh MJ: Complexes of adenovirus with polycationic polymers and cationic lipids increase the efficiency of gene transfer in vitro and in vivo. J Biol Chem 272: 6479-6489, 1997.

40. Dietz AB and Vuk-Pavlović S: High efficiency adenovirus-mediated gene transfer to human dendritic cells. Blood 91: 392-398, 1998.

41. Christopherson KW II, Campbell JJ and Hromas RA: Transgenic overexpression of the CC chemokine CCL21 disrupts T-cell migration. Blood 98: 3562-3568, 2001.

42. Förster R, Schubel A, Breitfeld D, Kremmer E, Renner-Müller I, Wolf $\mathrm{E}$ and Lipp M: CCR7 coordinates the primary immune response by establishing functional microenvironments in secondary lymphoid organs. Cell 99: 23-33, 1999.

43. Bromley SK, Thomas SY and Luster AD: Chemokine receptor CCR7 guides T cell exit from peripheral tissues and entry into afferent lymphatics. Nat Immunol 6: 895-901, 2005.

44. Bacon KB, Premack BA, Gardner P and Schall TJ: Activation of dual $\mathrm{T}$ cell signaling pathways by the chemokine RANTES. Science 269: 1727-1730, 1995.

45. Dairaghi DJ, Soo KS, Oldham ER, Premack BA, Kitamura T, Bacon KB and Schall TJ: RANTES-induced T cell activation correlates with CD3 expression. J Immunol 160: 426-433, 1998.

46. Appay V, Dunbar PR, Cerundolo V, McMichael A, Czaplewski L and Rowland-Jones S: RANTES activates antigen-specific cytotoxic T lymphocytes in a mitogen-like manner through cell surface aggregation. Int Immunol 12: 1173-1182, 2000.

47. Guo Z, Zhang M, Tang $\mathrm{H}$ and Cao X: Fas signal links innate and adaptive immunity by promoting dendritic-cell secretion of $\mathrm{CC}$ and CXC chemokines. Blood 106: 2033-2041, 2005.

48. Flanagan K, Moroziewicz D, Kwak H, Hörig H and Kaufman HL: The lymphoid chemokine CCL21 costimulates naive T cell expansion and $\mathrm{Th} 1$ polarization of non-regulatory $\mathrm{CD} 4^{+} \mathrm{T}$ cells. Cell Immunol 231: 75-84, 2004.

49. Marsland BJ, Bättig P, Bauer M, Ruedl C, Lässing U, Beerli RR, Dietmeier K, Ivanova L, Pfister T, Vogt L, Nakano H, Nembrini C, Saudan P, Kopf M and Bachmann MF: CCL19 and CCL21 induce a potent proinflammatory differentiation program in licensed dendritic cells. Immunity 22: 493-505, 2005. 